\title{
Posttraumatic Seroma Mimicking Tibial Edema in a Patient With Frequently Relapsing Nephrotic Syndrome
}

\author{
Hiro Matsukura $^{\text {a, b }}$, Emi Takano ${ }^{\text {a }}$, Tsubura Okuda ${ }^{\text {a }}$ Emiko Iwata ${ }^{a}$
}

\begin{abstract}
Seromas are collections of serous fluid. A Japanese girl with refractory nephrotic syndrome showed posttraumatic seroma following a large soft ball hitting at the tibia. The seroma was misunderstood as tibial edema, but the seroma did not disappear after archiving complete remission. After the puncture, the seroma shrank and no flareup occurred. Hypoalbuminemia associated with nephrotic syndrome may not only cause tibial edema, but also make the patient prone to seroma formation after trauma.
\end{abstract}

Keywords: Bursitis; Edema; Hypoalbuminemia; Magnetic resonance imaging; Nephrotic syndrome; Seroma

\section{Introduction}

A seroma is defined as a sterile accumulation of serum in a circumscribed location in the tissue [1]. The seroma usually occurs as a complication of surgery, but can also be seen posttrauma [2]. Seroma formation is thought to occur as plasma from local hemorrhage and other serous fluid accumulates at the site of tissue removal or disruption from surgery or trauma [2]. The fluid collects within scar tissue and can accumulate to a large size causing discomfort or can be unsightly [2]. Hypoalbuminemia associated with nephrotic syndrome (NS) may make the patient prone to seroma formation. Herein, we present a case of posttraumatic seroma mimicking tibial edema in the patient with steroid dependent and frequently relapsing NS.

\section{Case Report}

The patient, now an 18-year-old Japanese girl, first presented with NS at the age of 2 years. She has been treated with predni-

\footnotetext{
Manuscript accepted for publication May 06, 2016

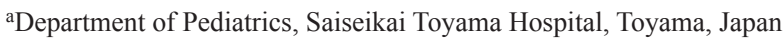
${ }^{b}$ Corresponding Author: Hiro Matsukura, Department of Pediatrics, Saiseikai Toyama Hospital, 33-1 Kusunoki, Toyama 931-8533, Japan.

Email: matsukura-npr@umin.org
}

doi: http://dx.doi.org/10.14740/ijcp248w solone according to the International Study of Kidney Disease in Children protocol [3] and promptly responded with resolution of NS. Withdrawing doses of prednisolone, she repeatedly relapsed and had never been off prednisolone. The renal biopsy showed minimal-change lesion. Cyclophosphamide treatment for 12 weeks at a dose of $2 \mathrm{mg} / \mathrm{kg} /$ day [4] failed to reduce her experiencing relapses. Relapses were treated with pulse steroid (500 $\mathrm{mg}$ of methylprednisolone IV for 3 days) followed by oral prednisolone [4]. After high school enrollment, she still showed steroid dependent and frequently relapsing NS. Her kidney function remained normal after 16 years follow-up. She was belonged to a softball team in her school and enjoyed playing catcher. Playing a game, a large softball accidentally hit her left tibia. A few days later, she noted a soft tissue mass at the left tibia. She thought that it must be usual tibial edema associated with NS. Serum total protein was 4.4 $\mathrm{g} / \mathrm{dL}$, albumin was $1.3 \mathrm{~g} / \mathrm{dL}$, and proteinuria was $3+$. She had another relapse. After archiving complete remission of NS with reduction of weight from 51 to $46 \mathrm{~kg}$, the subcutaneous mass did not improve. White blood cell count was $5,100 / \mathrm{mm}^{3}$ and C-reactive protein was $0.3 \mathrm{mg} / \mathrm{dL}$. A $5 \times 7 \mathrm{~cm}$ soft tissue mass was located at the left lower tibia without tenderness (Fig. 1a). Roentgenography revealed no fracture of the tibia (Fig. 1b). Magnetic resonance imaging (MRI) showed posttraumatic soft tissue cysts (Fig. 2a, b). By a needle puncture, clear $40 \mathrm{~mL}$ of fluid was withdrawn, but no culture was obtained. After the puncture, the subcutaneous tumor promptly

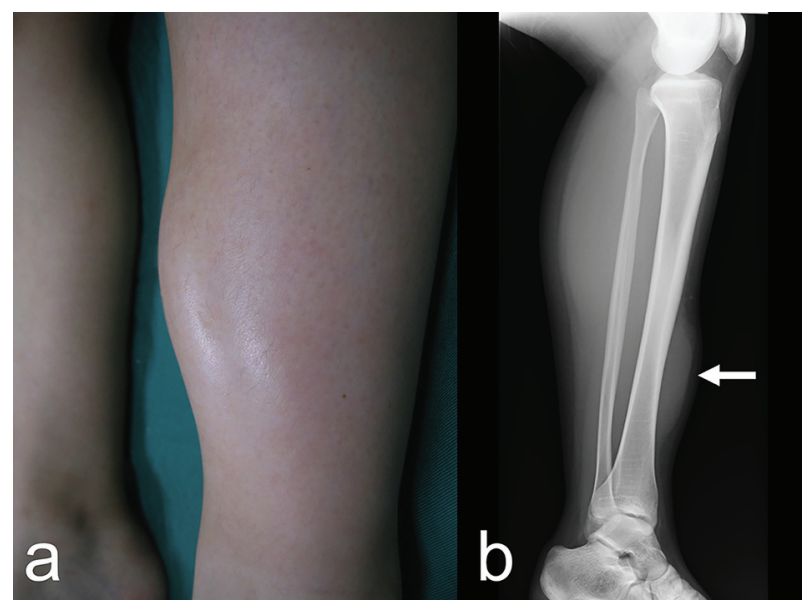

Figure 1. (a) A large soft tissue mass is present on the left lower tibial region. (b) Roentgenography of the left tibia shows the subcutaneous mass, but no bone fracture. 


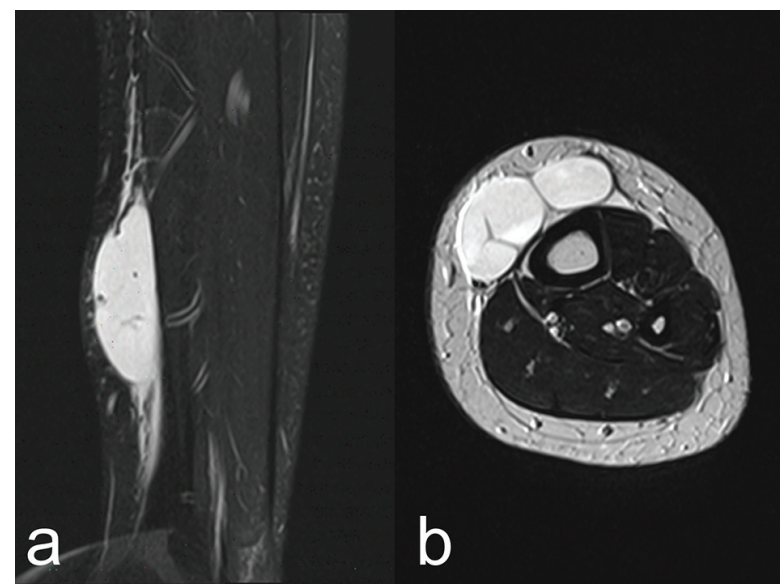

Figure 2. Magnetic resonance T2-weighted images show a hyper-intense mass separated by septum, containing debris. (a) Sagittal section. (b) Axial section.

shrank and no flare-up occurred.

\section{Discussion}

We found two important clinical issues. Lower tibial soft tissue mass is not tibial edema, but posttraumatic seroma. Hypoalbuminemia would make the patient prone to seroma formation following trauma.

First, the soft tissue mass is not tibial edema, but posttraumatic seroma. After archiving complete remission with 5 $\mathrm{kg}$ of reduction of weight, the subcutaneous mass showed no improvement; otherwise, it had to be gone. Relapses of NS occurred almost every month and she suffered from tibial edema. She must misunderstand the subcutaneous mass as usual pitting edema at the tibia because of no tenderness and arthralgia. No fracture of the tibia was noted and MRI confirmed a diagnosis of posttraumatic seroma in the tibia.

Second, hypoalbuminemia would make the patient prone to seroma formation following trauma. In cases of hypoalbuminemia, diffuse or localized edema may occur. Furthermore, trauma may result in the occurrence of a pouch filled with hematoma or seroma. At the accidental event, she had another relapse of NS and hypoalbuminemia. Hypoalbuminemia may play a role to make the patient prone to seroma formation following the large soft ball hitting.

In the absence of inflammation, focal bacterial infection is unlikely, although the culture of the punctured fluid was not performed. Prepatellar and anserine bursitis are two major common bursae in the knee joint [5-7]. The pretibial bursa is located more proximally between the tibial tuberosity and the skin at the level of the distal patellar tendon $[5,6]$. The affected lesion is located at the junction of the middle and lower thirds of the tibia, where no bursae are present. Prolonged stress on the bursa can develop acute bursitis [6]. If her play activities or incorrect posture would cause bursitis, more common types of bursitis would occur in the knee.

\section{Conclusion}

The Japanese girl presents with posttraumatic seroma mimicking tibial edema. She has suffered from steroid dependent and frequently relapsing NS. Hypoalbuminemia may not only cause tibial edema, but also prone to seroma formation after trauma in this case.

\section{Conflicts of Interest}

The authors declare that they have no conflict of interest.

\section{References}

1. On-line source: Data Sciences International: Seromas: Cause and Management. https://www.datasci.com/docs/ technical-notes/392-0027-002-rev-61.pdf?sfvrsn=2.

2. On-line source: Radiopaedia.org: Seroma. http://radiopaedia.org/articles/seroma.

3. The primary nephrotic syndrome in children. Identification of patients with minimal change nephrotic syndrome from initial response to prednisone. A report of the International Study of Kidney Disease in Children. J Pediatr. 1981;98(4):561-564.

4. Niaudet P, Boyer O. Idiopathic Nephrotic Syndrome in Children: Clinical Aspects. In: Avner ED, Harmon WE, Niaudet P, Yoshikawa N, eds. Pediatric Nephrology. Volume 1. 6th ed. Springer-Verlag Berlin Heidelberg, 2009; p. 667-702.

5. On-line source: UpToDate: Patient information: Bursitis (Beyond the Basics). http://www.uptodate.com/contents/ bursitis-beyond-the-basics.

6. On-line source: Merck Manual Professional: Bursa, Muscle, and Tendon Disorders: Bursitis. http://www.merckmanuals.com/professional/musculoskeletal-and-connective-tissue-disorders/bursa-muscle-and-tendon-disorders/ bursitis.

7. Valeriano-Marcet J, Carter JD, Vasey FB. Soft tissue disease. Rheum Dis Clin North Am. 2003;29(1):77-88, vi. 